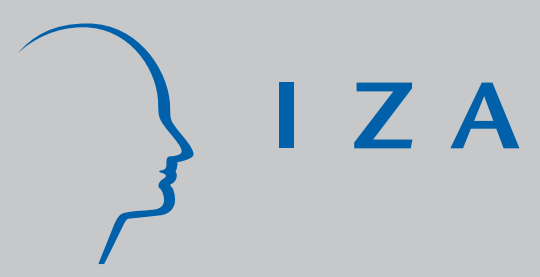

IZADP No. 3785

Estimating the Effect of Student Aid on College Enrollment: Evidence from a Government Grant Policy Reform

Helena Skyt Nielsen

Torben Sørensen

Christopher Taber

October 2008 


\title{
Estimating the Effect of Student Aid on College Enrollment: Evidence from a Government Grant Policy Reform
}

\author{
Helena Skyt Nielsen \\ $A K F$, Aarhus University and IZA \\ Torben Sørensen \\ Aarhus University \\ Christopher Taber \\ University of Wisconsin-Madison and NBER
}

Discussion Paper No. 3785

October 2008

\author{
IZA \\ P.O. Box 7240 \\ 53072 Bonn \\ Germany \\ Phone: +49-228-3894-0 \\ Fax: +49-228-3894-180 \\ E-mail: iza@iza.org
}

\begin{abstract}
Any opinions expressed here are those of the author(s) and not those of IZA. Research published in this series may include views on policy, but the institute itself takes no institutional policy positions.

The Institute for the Study of Labor (IZA) in Bonn is a local and virtual international research center and a place of communication between science, politics and business. IZA is an independent nonprofit organization supported by Deutsche Post World Net. The center is associated with the University of Bonn and offers a stimulating research environment through its international network, workshops and conferences, data service, project support, research visits and doctoral program. IZA engages in (i) original and internationally competitive research in all fields of labor economics, (ii) development of policy concepts, and (iii) dissemination of research results and concepts to the interested public.
\end{abstract}

IZA Discussion Papers often represent preliminary work and are circulated to encourage discussion. Citation of such a paper should account for its provisional character. A revised version may be available directly from the author. 


\section{ABSTRACT}

\section{Estimating the Effect of Student Aid on College Enrollment: Evidence from a Government Grant Policy Reform*}

In this paper, we investigate the responsiveness of the demand for college to changes in student aid arising from a Danish reform. We separately identify the effect of aid from that of other observed and unobserved variables such as parental income. We exploit the combination of a kinked aid scheme and a reform of the student aid scheme to identify the effect of direct costs on college enrollment. To allow for heterogeneous responses due to borrowing constraints, we use detailed information on parents' assets. We find that enrollment is less responsive than found in other studies and that the presence of borrowing constraints only deters college enrollment to a minor extent.

JEL Classification: $\quad$ 122, J24

Keywords: college attendance, educational subsidies, reform, kink regression

Corresponding author:

Helena Skyt Nielsen

Department of Economics

University of Aarhus

Bartholins Allé 4, Bld. 322

DK-8000 Aarhus C

Denmark

E-mail: hnielsen@econ.au.dk

\footnotetext{
* We appreciate comments from Ron Ehrenberg, Julien Grenet, Marieke Huysentruyt, Søren LethPetersen, from participants at ASSA 2007, ESPE 2007, SOLE 2008, TAPES 2008, and seminar participants at the University of Amsterdam, University of Copenhagen, Aarhus University, University of Washington, and at AKF. The project has been supported by the Danish Research Agency (grant no. 2117-05-0076). The usual disclaimer applies.
} 


\section{Introduction}

An increase in educational subsidies is expected to increase college enrollment. Despite that substantial educational subsidies are already in place, previous empirical work suggests the elasticity is large. Empirical studies for the U.S. find that the magnitude of the effect is such that a $\$ 1,000$ increase in the annual educational subsidy increases enrollment by roughly 3-5 percentage points (see e.g. Dynarski, 2003; Leslie and Brinkman, 1988; Manski and Wise, 1983; McPherson and Shapiro, 1991). The purpose of this paper is to investigate the responsiveness of the demand for college to changes in student aid by exploiting some useful exogenous variation in Danish data.

The crucial issue in studies of the effect of financial aid on enrollment is to separately identify the effect of aid from that of other observed and unobserved variables such as parental background. First, student aid is often means tested against parental income and other socioeconomic variables. Second, responsiveness of demand for college to changes in student aid is likely to vary with parental background for many reasons. In particular, one might expect college enrollment to be particularly responsive to educational subsidies among families who are borrowing constrained (see e.g. Cameron and Taber, 2004). In this paper we show how a combination of a kinked aid scheme and a reform of the student aid scheme can be exploited to identify the effect of direct costs on college enrollment accounting for borrowing constraints. We show that, theoretically, the first characteristic is sufficient to identify the effect of interest.

The reform of the Danish student aid scheme was implemented for the college cohort starting september 1988 and consisted of two major changes: it eliminated the means-testing and - most importantly - it raised the level of grants by more than $25 \%$ for all students above 19 years of age. The change in subsidy varied across parental background. After the reform, educational subsidies universally covered almost all students throughout their college education at a generous level. ${ }^{1}$

Children with poor parents (henceforth: poor kids) are often expected to be more responsive to educational subsidies than the children of rich parents (henceforth: rich kids). This finding may work through (at least) three different channels. (1) Poor kids are more likely to be borrowing constrained, therefore, if increased subsidies reduce the extent of these

\footnotetext{
${ }^{1}$ We use the terms grant, stipend and student aid interchangeably.
} 
constraints, poor kids may be more responsive to a policy change. (2) Poor kids may receive lower schooling contingent transfers from their parents. If public transfers crowd out some schooling contingent parental transfers, a policy change may have a smaller impact on rich kids. (3) Poor kids receive less non-labor income transfers from their parents over their life cycle than rich kids. That may be due to lower non-contingent transfers from their family when they are young or due to less bequests. This implies that the marginal utility of income is higher for poor kids than for rich kids who have higher non-labor income. As a result, they are more sensitive to a reduction in costs. As is common in most of the literature, we implicitly assume that children and their parents form a dynasty with common interests, and hence we are not able to separately identify the effect of (2) and (3). Our efforts are focused on accounting appropriately for channel (1), namely, the effect of borrowing constraints.

In a more direct approach we adopt the low liquid asset measure, which was suggested by Zeldes (1989) and succesfully applied by Leth-Petersen (2006), to control for borrowing constraints. They argue that the ratio of liquid assets to income is a powerful way to identify the households who potentially face a binding credit constraint.

We use Danish register-based data for the cohorts graduating from high school in 1985 to 1990. In this way we have observations both before and after the reform. We rank individuals according to the index of parental income which determines eligibility for student aid, and match post-reform individuals with pre-reform individuals at the same place in the income distribution. ${ }^{2}$ The fact that the relationship between this measure of parental income - and hence the rank in the distribution of parental income - and the stipend is nonlinear, helps us to identify the relationship of interest. We show formally that the relationship between family income and college enrollment should jump at the kink point which allows us to identify the effect of the reform. Basically, we analyze whether the family income/college enrollment relationship changed systematical differently around the kink points.

We find that the subsidy did increase college enrollment, but to a smaller extent compared to previous work on US data. The point estimates indicate that a $\$ 1,000$ increase in the yearly stipend increases college enrollment by 1.35 percentage points. This somewhat smaller effect might partly be caused by the fact that total subsidies were and still are larger in

\footnotetext{
${ }^{2}$ This avoids making restrictive untestable assumptions about income growth for the parents over the six year period. We are implicilty making the assumption that (counterfactual) eligibility for student aid for the post-reform individuals had they graduated from high school before the reform, is determined by their place in the income distribution.
} 
Denmark than it has ever been in the US. We find some evidence that borrowing constraints deter enrollment. The reported results are conditional on an assumption that the supply is completely flexible. If a supply constraint has been binding, a demand increase should show up in 'prices' which (in the Danish case) would be entry requirements in terms of GPA. We argue that the demand response did not affect prices significantly.

To gain further insight and improve the interpretation of the reduced form results, we set up and estimate a simple structural model. Simulating various policy counterfactuals, the subsidy level is found to be important for college enrollment. Borrowing constraints do not appear to be important in Denmark at this time, but this is in large part due to the substantial subsidy already in place.

The remainder of this paper is organized as follows: Section 2 surveys the literature. Section 3 describes the reform while section 4 documents the data. Section 5 presents the empirical analysis and section 6 concludes the paper.

\section{Existing Literature}

The literature attempting to identify the effect of costs on college attendance is long and diverse. In an older review of the literature, Leslie and Brinkman (1988) conclude that the estimated effect on college attendance of a $\$ 1,000$ dollar aid increase ranges from three to five percentage points. The results from the earlier studies are, however, likely to be flawed by poor identification, as aid is correlated with numerous observable and unobservable variables.

Comparing enrollment rates across states, Kane (1995) finds that a \$1,000 dollar difference in costs of public 2-year college is associated with a 19-29\% difference in enrollment rates (8-16 percentage points) among 18-19 year-olds. Conditioning on 2-year tuition, the effect of tuition in public 4-year college is positive, although insignificant, indicating that the marginal price determining whether or not people attend college at all is public 2-year college tuition and not 4-year college tuition. The major weakness of this cross-state comparison is that identification is based upon differences between states which have been fairly stable over time, making it difficult to separate the effect of tuition from other fixed inter-state differences. Exploiting within-state differences in public tuition increases since 1980, the same study estimates a 3.5 percentage point drop in public undergraduate enrollment following a $\$ 1,000$ dollar increase in public 2-year tuition. Furthermore, the gap in enrollment between 
high- and low-income youth grew the most in the states with the largest tuition increases, hinting at the presence of borrowing constraints. Surprisingly, the study finds no significant effect of implementing the federal means-tested Pell Grant programme in the mid-seventies, leading to the hypothesis of supply constraints muting the effect of the supposedly increased college demand on actual enrollment. This finding is consistent with the influential study of Hansen (1983). Later, Turner (1998) rationalized this missing effect by large aid budget institutions "undoing" the targeting of the federal grants.

Later, McPherson and Schapiro (1991) exploit more years of observations and find a significant effect of changes of the Pell Grant. A \$1,000 dollar increase in net costs (19781979 dollars) is estimated to reduce the enrollment of low-income students by 6.8 percentage points.

Exploiting annual micro-data from the CPS, Seftor and Turner (2002) examine the effect of changes in the Pell Grant programme on mature students, and find this group to be more responsive to changes than traditional college-goers. More severe borrowing constraints for the mature students might justify this.

The elimination of the Social Security Student Benefit Program, which subsidized students of deceased, disabled, or retired parents, provides Dynarski (2003) with a source of exogenous variation in schooling costs. The effect of a $\$ 1,000$ dollar subsidy on the enrollment probability is estimated to be 3.6 percentage points using a difference-in-differences identification strategy.

The previously mentioned results mainly apply to students from low-income families, in that the youth subsidized by the Pell programme and to a large extent also those subsidized by the Social Security Student Benefit Program are from low-income families. Dynarski (2000) studies the Georgia HOPE programme, which mainly affected middle- and upperincome students because any federal (means-tested) grants were deducted from the HOPE stipends. This programme allowed free attendance at Georgia's public colleges for state residents with at least a B average in high school. Using out-of-state as well as in-state control groups, Dynarski finds that a $\$ 1,000$ dollar subsidy increase raise enrollment rates of middle- and upper-income students by 4-6 percentage points.

When focus shifts to the relationship between a single educational institution's grant and tuition scheme and enrollment into the institution, the results are mixed. Linsenmeir, Rosen and Rouse (2006) find a small, insignificant effect on low-income youth of converting 
subsidized loans into pure grants, although there might be a significant effect on minorities. Shin and Milton (2006) argue that the observed empirical anomaly that tuition and enrollment have risen together over a time span is due to omitted variables. They perform their analysis at the college level, including competitive institutions tuition level and the wage premium as control variables, and find the enrollment changes during 1998-2002 to be unaffected by tuition and financial aid. Van der Klaauw (2002) exploits discontinuities in the relation between a university's financial aid offer and a continuous ability measure. Based on the regression discontinuities, Van der Klaauw reveals an enrollment elasticity of $8.6 \%$ for applicants who also filed for federal aid, whereas the elasticity for non-filers is estimated to be $1.3 \%$. This difference in responsiveness is taken as an indication of borrowing constraints.

In a European context, Baumgartner and Steiner (2006) implement a difference-indifferences estimator in a discrete-time hazard rate model to evaluate the effect of the German student aid reform of 2001, which both increased the amount of subsidy received and the coverage of the programme. Based on a fairly small sample, they find small and insignificant effects.

Changes of educational policy often affect a significant part of the population. Therefore, it is crucial to consider the supply side of the sector and not only the demand side, and in addition, general equilibrium effects might flaw the results derived from a partial analysis. Supply side considerations are rarely discussed explicitly in the studies, although e.g. Turner (1998) and Kane (1995) point to supply side effects as causing otherwise counter-intuitive results. General equilibrium effects are analyzed by Heckman, Lochner and Taber (1998), who find that taking the tax financing of the college grant and the effect on relative wages into account, may reduce the effect of tuition on enrollment by a factor 10 .

There is a growing literature on borrowing constraints with no clear consensus on their importance. Cameron and Heckman $(1998,2001)$ look at the effect of income on college completion. They find that after controlling for AFQT, the effects of family income are quite small. They argue that short run credit constraints do not seem to be a major component determining schooling levels. Carneiro and Heckman (2002) follow up on this work that credit constraints do not appear to be important, but claim that $8 \%$ of the population of the united contraints may be subject to short run credit constraints. Belley and Lochner (2007) extend this approach to consider both the NLSY79 and the NLSY97. They find much stronger income effects for the 1997 data. They argue that it is hard to reconcile these facts 
without appealing to credit constraints.

Shea (2000) argues that borrowing constraints are not important. His approach is to find family income variation that seems exogenous such as union status and job loss. He finds that these factors do not appear to be correlated with schooling. Keane and Wolpin (2001) estimate a discrete dynamic programming model of schooling, work, and savings. They find existence of borrowing constraints, but also find that relaxing them would have very little effect on college enrollment. Stinebrickner and Stinebrickner (2009) look at this issue by asking students enrolled at Berea college directly about whether they would accept a fair market loan and look at the relationship between the answer to this question and subsequent drop out behavior. While there is a relationship, they conclude that credit constraints are not a very important factor. Brown, Scholz, and Seshadri (2007) find quite different results. They develop a model of parental transfers to children and test the implications of the model. Specifically, they notice that financial aid decisions depend on the number of siblings currently enrolled in college. They use this variation to show that credit constrained people respond more strongly to this interaction than others leading them to conclude that the credit constraints appear to be important.

Our contribution is twofold. First, since the reform of the student aid scheme is universial, we apply an identification strategy which does not rely on the existence of a classic control group not exposed to policy changes as many of the previous studies do. Second, we introduce a new approach to deal with heteregenous responses due to credit constraints. We exploit detailed information on the asset portfolios of the parents to directly identify possible liquidity constraints among potential students.

\section{The Reform}

To identify the effect of educational subsidies on enrollment into college, we exploit a reform of the Danish Government Grant Policy which took place in 1988 and which in aggregate numbers more than doubled the amount of study grants awarded. ${ }^{3}$ In Denmark, the available college educations can be grouped into three categories: short-cycle, medium-cycle and long-cycle higher education programmes. Table 1 gives a brief overview of the three. In this paper, we focus on enrollment into any college education. Exploiting the differences between

\footnotetext{
${ }^{3}$ According to the Statistical Yearbooks (1984-1991) the amount of study grant awarded for higher education increased by $101 \%$ (after deflation).
} 
the three cycles of education is left as a natural, although not immediately straight forward, extension of the paper. The reform may of course also have influenced, for instance, consumption while in college, duration to completion and the extent of work while studying. ${ }^{4}$ In this paper, we focus on the effect on college enrollment.

All colleges are public institutions and free of charge. Student grants are universal in the sense that they are given to all students admitted to recognized educational institutions independently of their qualifications. There is an upper limit on the amount of wage income allowed. The grant program is well known, the application procedure is simple, and therefore, the take-up rate is close to $100 \% .^{5}$ Grants are means-tested for students below a certain age limit, whereas students above the age limit receive grants independently of their parents' income. For the present research project, we have access to the means-testing algorithm, and the exact income measures needed to check for eligibility.

Before the reform the subsidy was means-tested based on the following index, $X$, for all individuals below a certain age limit: ‘

$$
\begin{aligned}
X= & \text { Mother's Income }+ \text { Father's Income } \\
& -a \times \text { Number of Siblings }+f(\text { Parent's Wealth }), \hat{E}
\end{aligned}
$$

where Income is taxable income, Number of Siblings denotes the number of siblings below the age limit who are undertaking a college education, $a$ is annually adjusted to account for inflation, and $f()$ is a nonlinear function of parents' wealth which also varies over time. We disregard individuals with divorced parents. Until 1987, the subsidy was means-tested for individuals below the age limit 22 . That is, until age 22 the subsidy depended on the index $X$, but all students age 22 and higher were eligible for the full subsidy. As a first step before the major reform of the student aid system, the subsidy was means-tested only for individuals below the age limit 20 in $1987 .^{6}$

The actual reform was announced in 1987 and it was implemented for the cohort starting at college September 1st, $1988 .^{7}$ After the reform, educational subsidies universally covered

\footnotetext{
${ }^{4}$ Joensen (2008) and Arendt (2008) have found a negative effect of grants on dropout from Danish data. Arendt (2008) explore this specific reform, he finds no effect of grant on completion.

${ }^{5}$ According to Danish Educational Support Agency (2000), 93\% of students at institutions for higher education received a state education grant for at least one month during their education. The residual consists of older students who either earn high wages or are eligible for more favorable public income transfers.

${ }^{6}$ The 1987 change was first negotiated in February 1986 and it was passed in June 1986 in due time to influence the decisions of the 1986 cohort.

${ }^{7}$ According to the Parliament's yearbooks the law was first proposed in Parliament on 18/11-1986, whereas
} 
almost all students throughout their college education. The level of economic support was high enough to suffice for living. The reform consisted of two major changes: First, it reduced the age limit of the means-testing to 19 years. This meant that only the very few students who were born after August 1st and followed the fastest possible way through the educational system were means-tested for the first one or two quarters of their studies. ${ }^{8}$ Second, the reform raised the levels of grants by more than $25 \%$ for all students above 19 years of age. The increase was largest for those who were not eligible for stipend before the reform. Those with the largest parental incomes - and therefore the largest values of $X$ went from no grant at all (as long as they were under the age of 22) to 48,968 DKK per year (2001 prices), which roughly compared to $\$ 6,000$ per year. ${ }^{9}$

In Figure 1, we sketch the influence of the reform on the aid scheme. The main content of the reform was to universally increase the level of the stipend. The lower line (beginning at $s_{1}$ ) represents the initial stipend while the higher (at level $s_{2}$ ) represents the post reform stipend. One can see that prior to the reform individuals with $X<x_{1}$ were eligible for the maximum benefit of $s_{1}$. This benefit started to phase out at level $x_{1}$ until level $x_{2}$. Students from families with $X>x_{2}$ received no stipend. After the reform everyone was eligible for the higher level. As a result, one can see that the net effect of the reform was larger for individuals for whom the pre-reform means-test was binding (i.e. $X>x_{1}$ ) but that the reform affected everyone.

To exploit the variation provided by the reform, we predict the amount of stipend individuals who are observed post-reform would be eligible for had they graduated before the reform. To avoid restrictive, untestable assumptions about income growth for the parents over the six year period, we make the assumption that (counterfactual) eligibility for student aid for the post-reform individuals had they graduated from high school before the reform, is determined by their position in the income distribution. Hence, we rank individuals according to the measure of parental income, $X_{i}$, which determines eligibility for student aid, and predict the amount of aid an individual would have been eligible for before the reform by assuming that his parents would have been at the same position in the income distribution

it was finally agreed upon on 23/4-1987 (see the Parliament's yearbook 1985-1986 and the Parliament's yearbook 1986-1987). Hence the 1987-cohort of high school graduates were the first ones to know about the reform when they made their career decisions.

${ }^{8}$ We exclude individuals who do not turn 19 in the year they graduate from high school. This group is small and they are likely to have a systematically different behaviour.

${ }^{9}$ The average exchange rate during 2001 was 8.32 USD to one DKK. 
at that time. Basically, we are controlling for the distribution of income and not allowing it to determine the effect of the reform. Using this approach, we implicitly assume that the placement in the income distribution is unaffected by the reform. As a consequence, we estimate the effect of the intention to treat rather than the actual treatment. Though, we do not expect behaviour determining the income of the parents to be affected considerably by this reform.

Let $S_{i}$ be the stipend individual $i$ would be eligible for if enrolling at high school graduation. We define the variable, $S_{i}^{\text {pre }}$ to be the stipend for which the individual would be eligible in $1985 .{ }^{10}$ Thus, for an individual from a pre-reform cohort, $S_{i}^{\text {pre }}=S_{i}$. We have the same administrative data used to determine the subsidy so we know this variable exactly. For an individual post reform, we use the following procedure:

\section{Calculate $X_{i}$}

2. Determine the quantile of $X_{i}$ for the current cohort

3. Obtain the corresponding quantile of $X_{i}$ for the pre-reform cohort, call it $x_{i}^{\text {pre }}$.

4. Calculate $S_{i}^{\text {pre }}$ as the subsidy corresponding to $X=x_{i}^{\text {pre }}$ using the 1985 rule.

Given the design of the grant scheme and the reform, the basic task we face is to separate the effect of stipend from parental income and cohort effects. Figure 1 illustrates that we have three different sources of variation in the stipend which could potentially identify the effect of interest. Before the reform, the grant varied within each cohort across $X$. Since the former is a function of the latter, using this source of variation for identification would, generally, require some strong functional form assumptions. The reform provides variation over time. We are, however, excluding two high school graduation cohorts (1987 and 1988) to avoid announcement effects, therefore, ending up with a considerable time span between the treatment group (post-reform high school graduates) and the control group (prereform graduates). Hence, directly comparing post-reform individuals to similar pre-reform individuals is obviously not a tempting strategy due to inter cohort variation. Ideally, one would like a control group not exposed to the reform to facilitate a difference-in-difference

\footnotetext{
${ }^{10}$ We take four years of grant as our measure of stipend. Due to the age limit, the total stipend received during college is in general not just a scaling of the one-year stipend. Hence, the planning horizon of the individual could be of relevance. In our present analysis, however, we lump the cycles together, so there are no natural measure for total stipend during education.
} 
strategy to prevent cohort or year effects from driving the results. However, the universal nature of the grant system and the reform preclude such a control, since all potential students are affected by the reform. Although we have no group who are unaffected by the reform, we still have variation in the stipend change provided by the reform. As seen in Figure 1, the change in stipend varies across individuals, and this is the source of variation we will exploit for identification.

\section{A Simple Model}

In this section we set up a simple model of the college going decision. The model is formulated to provide a straightforward link between the identification of the model and the variation in the data. The model modifies the model in Cameron and Taber (2004).

\subsection{Basic Model}

Individuals derive utility from consumption and tastes for non-pecuniary aspects of schooling. These non-pecuniary tastes could represent the utility or disutility from school itself or preferences for the menu of jobs available at each level of schooling. Assuming agents have $\log$ utility over consumption in each period, lifetime utility for schooling level $S$ is given by

$$
U_{s}=\sum_{t=0}^{\infty} \delta^{t} \log \left(c_{t}\right)+\nu_{S}
$$

where $c_{t}$ is consumption at time $t, v_{S}$ represents non-pecuniary tastes for schooling level $S$, $\delta$ is the subjective rate of time preference. Note that we have abstracted from uncertainty in the model.

We restrict the analysis to the binary choice of whether to go college or not. Individuals choose schooling so that

$$
S=\arg \max \left\{U_{S} \mid S \in\{0,1\}\right\}
$$

where 1 represents going to college, 0 represents not going to college.

Cameron and Taber (2004) assume that people borrow and lend at rate $\frac{1}{\delta}$ after school,

but at rate $R$ while in school. For borrowing constrained students $R>\frac{1}{\delta}$, whereas for non borrowing constrained students $R=\frac{1}{\delta}$. In their model which approximated the U.S., income is zero while is school so students must borrow while in school. 
However, this model is not appropriate in the Danish case. Since students may be able to subsist on the subsidy, they may not have to borrow while in school and may actually save. We augment the Cameron-Taber model in a straightforward way. Following them, we assume that the borrowing rate while in school is $R$. However if students save while in school, they do so at the market rate rate $\frac{1}{\delta}$.

Let $W_{1}$ and $W_{0}$ be the present values of earnings discounted to the time of labor market entry for college goers and non-college goers, respectively, and $f$ is income during college. There are three possibilities in this model depending on the level of $f$ :

- If $f$ is sufficiently low, students will borrow while in school at rate $R$

- If $f$ is sufficiently high, students will save for the future while in school at rate $1 / \delta$

- For intermediate values, the student will neither borrow nor lend, but consume $f$ while in school.

Those who are not borrowing constrained can borrow and lend at rate $1 / \delta$. For the individual who are potentially constrained, we assume that $R$ is sufficiently large that borrowing constrained people will not borrow during college. That is, for tractability, we assume that only the second or third of the possibilities above actually occur.

Letting $V_{1 i}$ be the utility from consumption if one goes to college. Then, for those that can borrow at the market rate:

$$
V_{1 i}=\frac{\log (1-\delta)}{1-\delta}+\left(\frac{1}{1-\delta}\right) \log \left(\delta W_{1}+f_{i}\right)
$$

For those that are potentially borrowing constrained

$$
V_{1 i}=\left\{\begin{array}{cc}
\log \left(f_{i}\right)+\delta\left[\frac{\log (1-\delta)}{1-\delta}+\left(\frac{1}{1-\delta}\right) \log \left(W_{1}\right)\right] & \text { if } f_{i}<\left(\delta W_{1}+f_{i}\right)(1-\delta) \\
\frac{\log (1-\delta)}{1-\delta}+\left(\frac{1}{1-\delta}\right) \log \left(\delta W_{1}+f_{i}\right) & \text { otherwise }
\end{array}\right.
$$

The condition $f_{i}<\left(\delta W_{1}+f_{i}\right)(1-\delta)$ denotes the cutoff for whether the individual is constrained or not. If it holds then the individual is borrowing constrained in the sense that if she were offered a loan at the market interest rate, she would choose to take it. Note that $f_{i}$ will consist, partly, of the educational subsidy received during college . Hence, the subsidy influences the schooling decision through two channels. Directly, by affecting the return to college and, indirectly, by potentially altering the borrowing constraint status of 
the individual. The importance of the subsidy for whether the individual is constrained or not depends on the resources otherwise available to the student during college.

To see the main prediction from the model, consider two individuals with exactly the same college lifetime income, $W_{1}$, but that one individual is borrowing constrained while the other is not. For the non-borrowing constrained student

$$
\frac{\partial V_{1 i}}{\partial f_{i}}=\left(\frac{1}{1-\delta}\right) \frac{1}{\delta W_{1}+f_{i}},
$$

while for the borrowing constrained student

$$
\frac{\partial V_{1 i}}{\partial f_{i}}=\frac{1}{f_{i}}
$$

Recall from above that the constraint binds when $f_{i}<\left(\delta W_{1}+f_{i}\right)(1-\delta)$ in which case borrowing constrained students will be more sensitive to changes in $f_{i}$ than will those that are not constrained. Furthermore, it is important to keep in mind that $f_{i}$ consists of both the subsidy and of other resources given to the parents while in school. This means that even among families that are borrowing constrained, children from wealthier families will

have higher values of $f_{i}$ and thus lower values of $\frac{\partial V_{1 i}}{\partial f_{i}}$. Thus the theory yields the following predictions:

1. All else equal, students from borrowing constrained families will be more sensitive to the subsidy than students who are not constrained.

2. All else equal, among students from borrowing constrained households, those with lower household resources will be more sensitive to the subsidy than those with more resources, as long as wealthier families give larger transfers to their children.

\section{Empirical Approach}

The goal of our work is to evaluate the effects of the reform. As should be clear from the model, a major complication of the work will be to incorporate borrowing constraints. We showed in the empirical section that individuals who are borrowing constrained will be particularly sensitive to changes in schooling subsidies. In this paper we evaluate the reform using both a difference-in-differences type of approach and a structural model. We demonstrate the close relationship between the two, and in particular, show that identification in 
the structural model is very closely linked to the difference-in-differences model. With this goal in mind, we begin with a very simple model and add parts until we reach the structural model.

From a glance at Figure 1, a natural simple estimation strategy appears. Prior to the reform some students were receiving large subsidies, but after the reform subsidies were the same across all groups. This has a simple prediction that we would expect to see a much large effect of the reform on those individuals who were previously receiving low subsidies than those that were receiving high subsidies.

There are a number of different ways to implement such a difference-in-differences model, but we find the following most convenient. It is easiest to think about identification of this model if income were binary. Assuming a probit model, we could estimate the model

$$
\operatorname{Pr}\left(C_{i}=1\right)=\Phi\left(\beta_{0}+\beta_{1} S_{i}+\beta_{2} R_{i}+\beta_{3} X_{i}\right)
$$

where $C_{i}$ is a dummy variable indicating college enrollment and $\Phi$ is the c.d.f. of a Standard Normal random variable. $S_{i}$ is the subsidy for which individual $i$ is eligible, and $R_{i}$ a reform dummy. Before the reform, $S_{i}$ would take two values depending on whether family income $\left(X_{i}\right)$ were high or low. After the reform it would take a third and higher value but be constant across individuals. The key parameter is $\beta_{1}$ which represents the response of college enrollment to a subsidy. Since prior to the reform $S_{i}$ is a function of $X_{i}$ so with only pre-reform data we can not separately identify $\beta_{1}$ from $\beta_{3}$. Furthermore, the reform dummy $\left(R_{i}\right)$ is like a time dummy in a standard difference-in-differences framework. Thus $\beta_{1}$ is identified purely from the extent to which those who received a larger increase in stipend due to the reform responded more strongly than those who experienced the smallest increase.

In practice $X_{i}$ is not binary and we have other variables on which to condition. Our base specification is

$$
\operatorname{Pr}\left(C_{i}=1\right)=\Phi\left(\beta_{0}+\beta_{1} S_{i}+\beta_{2} R_{i}+\beta_{3} X_{i}+\beta_{4} S_{i}^{\text {pre }}+\beta_{5}^{\prime} Z_{i}\right),
$$

where $S_{i}^{\text {pre }}$ is the pre-reform subsidy described in the previous specification.

There is a major problem with this approach. Our economic model indicates that borrowing constrained individuals will tend to be more sensitive to subsidies than non-borrowing constrained individuals. Furthermore, within borrowing constrained families, those with lower family resources will tend to be more responsive. This is problematic because the key 
assumption justifying the difference-in-differences approach is that there is no interaction between the reform and $X_{i}$. However, the theory tells us that one should expect such an interaction. We address this problem in two separate ways.

Our first approach is apparent from again looking at figure 1. The form of the subsidy is far from smooth at the two kink points. By contrast, one would expect the relationship between $X_{i}$ and borrowing constraints to be smooth near the kink points. In the appendix we formalize this form of nonparametric identification near the kink point. In practice one can implement this idea just by allowing an interaction between the reform and a smooth function of $X_{i}$. That is one can estimate a model such as

$$
\operatorname{Pr}\left(C_{i}=1\right)=\Phi\left(\beta_{0}+\beta_{1} S_{i}+\beta_{2} R_{i}+\beta_{3} g_{1}\left(X_{i}\right)+\beta_{4} S_{i}^{p r e}+\beta_{5}\left(R_{i} \times g_{2}\left(X_{i}\right)\right)+\beta_{6}^{\prime} Z_{i}\right),
$$

where $g_{1}$ and $g_{2}$ are flexible functional forms.

Our second approach is to make use of the low liquid asset indicator we described above. It seems reasonable to believe that those individuals who have high liquid assets are not borrowing constrained and those with low liquid assets are potentially constrained. We can then look at both the effects of the program on the non-constrained as well as examine the importance of borrowing constraints by examining the difference in the program on the two different groups. To see the intuition for identification, again consider the binary income case. We could estimate the fully interacted model

$$
\begin{gathered}
\operatorname{Pr}\left(C_{i}=1\right)=\Phi\left(\beta_{0}+\beta_{1} S_{i}+\beta_{2} R_{i}+\beta_{3} X_{i}+\beta_{4} D_{i}+\beta_{5}\left(D_{i} \times S_{i}\right)\right. \\
\left.+\beta_{6}\left(D_{i} \times R_{i}\right)+\beta_{7}\left(D_{i} \times X_{i}\right)\right)
\end{gathered}
$$

We have eight different groups and eight different parameters so the model is just identified and the source of the identification is the same as in the simple model. In practice we have a continuous model and the base specification we use is the following:

$$
\begin{aligned}
\operatorname{Pr}\left(C_{i}=1\right)= & \Phi\left(\beta_{0}+\beta_{1} S_{i}+\beta_{2} R_{i}+\beta_{3} X_{i}+\beta_{4} S_{i}^{\text {pre }}+\beta_{5} D_{i}+\beta_{6}\left(D_{i} \times S_{i}\right)\right. \\
& \left.+\beta_{7}\left(D_{i} \times R_{i}\right)+\beta_{8}\left(D_{i} \times X_{i}\right)+\beta_{9}^{\prime} Z_{i}\right) .
\end{aligned}
$$

Before discussing the structural model consider specification (5) in terms of the model we exposited in section 4. One insight from the model was that the borrowing constraint should bind more tightly for poorer families. This means that for borrowing constrained people the effect of the subsidy should vary with family income. However, for non-borrowing 
constrained it should not. Ideally we would want three treatment effects, one for those who are not borrowing constrained, a second for the high income borrowing constrained, and a third for the low income borrowing constrained. However specification (5) does not allow for this. It allows for two "treatment effects," $\beta_{1}$ for individuals who are not borrowing constrained and $\beta_{1}+\beta_{6}$ for those who are. Ideally we would like to add a third possibility by including a $S_{i} \times D_{i} \times X_{i}$ interaction into the model. However that would require 9 different parameters, but we only have 8 separate groups in the binary case so that model would not be identified. However, we can identify that model under one additional assumption. As mentioned above, the key assumption justifying the difference-in-differences model is that the time trend does not vary with $X_{i}$. It seems completely reasonable to us to also assume that the time trend does not vary with $D_{i}$. In that case, in the difference-in-differences framework, we could think of estimating the model

$$
\begin{gathered}
\operatorname{Pr}\left(C_{i}=1\right)=\Phi\left(\beta_{0}+\beta_{1} S_{i}+\beta_{2} R_{i}+\beta_{3} X_{i}+\beta_{4} D_{i}+\beta_{5}\left(D_{i} \times S_{i}\right)\right. \\
\left.+\beta_{6}\left(D_{i} \times S_{i} \times R_{i}\right)+\beta_{7}\left(D_{i} \times X_{i}\right)\right) .
\end{gathered}
$$

Again we have 8 parameters and 8 unknowns and it is straightforward to show that this model is identified. Identification of this specification will turn out to be analogous to identification of the structural model.

The problem with specification (7) is that while it provides a clear description of the data, it is difficult to interpret the parameters. For example the parameters themselves have little economic meaning so it is difficult to say whether they are large or small. By using a structural model we can present parameters that are interpretable and can use the model to simulate policy counterfactuals. Of course, in doing so we are making stronger assumptions in that we are taking the model as true, so this represents the standard tradeoff of stronger assumptions but a more powerful model.

Next we describe the econometric implementation of the structural model presented in section 4. To keep things simple we specify the first period income as

$$
f_{i}=S_{i}+\gamma_{0}+\gamma_{1} X_{i}
$$

where we allow students to have some other assets while young which can depend on family resources proxied by $X_{i}$. We assume that these assets are not schooling dependent-that is the family will provide the resources to the children whether they go to college or not. Let 
$W_{1 i}$ and $W_{0 i}$ be our estimate of the present value of earnings of individual $i$ as a high school or college graduate. Given knowledge of $W_{1 i}, W_{0 i}, f_{i}$, and $\delta$, one can calculate $V_{0 i}$ and $V_{1 i}$.

We next assume that we can write the difference in non-pecuniary tastes across schooling levels as

$$
\begin{aligned}
\nu_{1 i}-\nu_{0 i} & =T_{i}^{\prime} \theta \sigma_{\varepsilon}+\varepsilon_{i} \\
\varepsilon_{i} & \sim N\left(0, \sigma_{\varepsilon}^{2}\right)
\end{aligned}
$$

where $T_{i}$ contains a vast set of controls including the borrowing constraints indicator, parents' income, and cohort indicators. Then the probability of going to college is

$$
\Phi\left(\frac{1}{\sigma_{\varepsilon}}\left[V_{1 i}-V_{o i}\right]+T_{i}^{\prime} \theta\right)
$$

The difference-in-differences model (7) above was specified in accordance with our structural model which is very similar except that we would replace the three parameters $\beta_{1}, \beta_{5}$, and $\beta_{6}$ with the three parameters $\sigma_{\varepsilon}, \gamma_{0}$, and $\gamma_{1}$. The rest of the parameters would be analogous to the taste parameters $\theta$ so that we would estimate

$$
\operatorname{Pr}\left(C_{i}=1\right)=\Phi\left(\theta_{0}+\frac{1}{\sigma_{\varepsilon}}\left[V_{1 i}-V_{o i}\right]+\theta_{1} R_{i}+\theta_{2} X_{i}+\theta_{3} D_{i}+\theta_{4}\left[D_{i} \times X_{i}\right]\right) .
$$

Thus identification of the structural model comes in virtually the same way as that for the difference-in-differences model. The advantage is that this model is easier to interpret and it can be used for policy simulation.

In practice, we have continuous variables and estimate a model that is analogous to (8), so we estimate the model

$$
\begin{aligned}
\operatorname{Pr}\left(C_{i}=1\right)= & \Phi\left(\theta_{0}+\frac{1}{\sigma_{\varepsilon}}\left[V_{1 i}-V_{0 i}\right]+\theta_{1} R_{i}+\theta_{2} X_{i}+\theta_{3} S_{i}^{p r e}+\theta_{4} D_{i}\right. \\
& \left.+\theta_{5}\left[D_{i} \times X_{i}\right]+\theta_{6}^{\prime} Z_{i}\right) .
\end{aligned}
$$

\section{Data}

\subsection{Data source}

We use a register-based data set covering the entire Danish population in the period 19832005. To this data set, we add information about educational event histories of individuals 
enrolled at educational institutions in the period 1973-2005. For the main part of the empirical analysis, we select a subsample consisting of high school students graduating in 1985-1990. We use only individuals who graduate at "normal" ages, which we define as 19-20 years. ${ }^{11}$ Furthermore, we select individuals who graduate from the ordinary high school track in order to get a homogenous sample of individuals with observed GPA. ${ }^{12}$

We augment the data with a prediction of the amount of grant which each individual would be eligible for, if they entered college immediately after high school graduation. We exclude individuals with divorced parents at the time of graduation as it is complicated to asses their eligibility status. We apply the algorithm which the authorities have used to compute grants for the students (see Section 3).

In order to account for potential borrowing constraints, we add information about the parents' liquid assets: the amount of assets held in cash, stocks, bonds, mortgage deeds and other assets. For individuals with self-employed parents at the time of high school graduation, accurate information about liquid assets is not available over the observation period. We choose to treat them as non-constrained as they are likely to have access to liquidity through their business. Our results are robust to this choice.

The resulting data set contains basic information about the individuals, grade point average from high school (GPA), their parental background including the income needed for means testing and the amount of liquid assets held at time of high school graduation.

\subsection{Data description}

In Table 2 we present enrollment rates at college for each of the high school graduation cohorts 1983-1990 by year. One can see that delaying college enrollment in Denmark is common. The table illustrates that roughly one half of the individuals who enroll within a five year period do so within the first year of high school graduation (39\% out of $73 \%$ for all cohorts). In the empirical analysis, we focus on accumulated enrollment one year after high school graduation such that pre-reform cohorts' enrollment decision occur prior to the announcement of the reform. It is important to keep this restriction of the analysis in mind. Strictly speaking, we cannot distinguish whether higher college enrollment within one year

\footnotetext{
${ }^{11}$ We do this to get a homogenous sample and to avoid interaction with the pre-reform means-testing age of 22 years. Roughly $80 \%$ of the students graduate at age $19-20$ years.

${ }^{12}$ About $60 \%$ of the high school students attend the traditional academic track. The rest of the high school students attend the business track, technical track, or another high school equivalent education.
} 
of graduation is due to a higher general enrollment rate or people enrolling earlier. However, this is what data allows, and it is nevertheless, a relevant policy parameter that we identify as policy makers are interested in inducing enrolment early after high school graduation. ${ }^{13}$

In the empirical analysis, we disregard the 1986 and 1987 cohorts. The reform of 1988 was announced in time for the 1987 cohort to adjust their behavior, and it was preceeded by a change in the age of eligibility for full grant independently of parental income (or more precisely: independently of the variable $X$ which was defined above) which was announced in time for cohort 1986 to adjust their behavior.

Table 2 indicates that the reform of 1988 has influenced enrollment since enrollment of cohorts graduating in years 1988-90 were systematically higher one year after high school graduation and onwards. However, we notice that mean enrollment varies substantially across the post-reform cohorts as well, indicating that it might be important to allow enrollment to vary flexibly across cohorts. In the empirical analysis, we tried to impose a placebo reform taking place one year later, and this experiment confirmed that the variation due to the actual reform is different from other cohort variation.

In Table 3, we present summary statistics by graduation year. We exclude the 7-8\% of individuals for whom information about the parents is unavailable. They are no different than the rest of the sample in terms of high school graduation age and college enrollment rates. Table 3 shows that the average high school graduation age is stable around 19.3 years, and that the average GPA is just above 8 and slightly increasing over the cohorts, which probably indicates grade inflation. ${ }^{14}$

To implement our model, we need to identify which students are borrowing constrained. We adopt a measure of borrowing constraints develped by Zeldes (1989) and used on Danish data by Leth-Petersen (2006). We get a powerful test of the effect of borrowing constraints by adopting a sample split that divides the sample into a group who are definitely not borrowing constrained versus a residual group who may be borrowing constrained. The assumption is that households who have high liquid assets relative to income are definitely not borrowing constrained, whereas households who have low liquid assets relative to income are potentially

\footnotetext{
${ }^{13}$ If we ignore the issue of borrowing constraints the data allow us to assess the effect on accumulated enrollment two and three years after high school graduation as well. Doing this we get similar estimates, indicating that the focus on accumulated enrollment one year after high school graduation does not limit the interpretability of the analysis considerably.

${ }^{14}$ At the relevant point in time, the Danish grade scale was as follows: $0,3,5,6,7,8,9,10,11$, and 13. The grades 6 and above are passed, and a medium performance is graded 8 .
} 
borrowing constrained. It is implicitly assumed that the low liquid assets households currently face a binding constraint because adverse income or consumption shocks have forced them to run down liquid assets in the past. As a measure of borrowing constraints, this is to be preferred over the measures that are usually applied: parents' income, parents' education or race (Cameron and Taber, 2004; Carneiro and Heckman, 2001), because it more accurately identifies households who are potentially constrained.

We construct a basic and an extreme indicator for being potentially borrowing constrained: The basic indicator, $D_{1}$, takes the value one if parents' liquid assets falls short of one months' income, whereas the extreme indicator, $D_{2}$, takes the value one if the parents' liquid assets falls short of two months' income. However, for parents who are self-employed, the amount of liquid assets is not registered and we set $D_{1}=0$ and $D_{2}=0$.

In Table 3, we report the two low liquid asset indicators, D1 and D2. Liquid assets include all non-housing assets ${ }^{15}$, that is cash, shares, bonds, mortgage deeds, and other assets. Roughly $30 \%$ of the sample have liquid assets below one months income, and roughly $40 \%$ have liquid assets below two months income. Those are the parents we regard as potentially borrowing constrained.

In Table 4, we present the average composition of the parents' portfolio by high school graduation cohort. The portfolios are dominated by cash and other assets (such as yachts, cars, campers and other taxable assets). In Table 5, we present the average composition of the parents' portfolio by the two low liquid asset indicators. It is seen that the potentially borrowing constrained individuals - with $\mathrm{D} 1=1$ or $\mathrm{D} 2=1$ - hold a much lower proportion of their wealth in stocks, bonds and mortgage deeds, and a higher proportion in other assets. The parents who have liquid assets of less than one months' income, and thereby falls short of the basic split, hold as much as $83 \%$ of their wealth in other assets. The parents who have liquid assets of less than two months' income, and thereby falls short of the extreme split, hold $72 \%$ of their wealth in other assets. The least constrained group with D2=0 hold $34 \%$ in cash, only $33 \%$ in other assets and roughly $9 \%$ in mortgage deeds, $12 \%$ in bonds and $13 \%$ in shares. It seems reasonable to us that a group with this portfolio composition would not be borrowing constrained. In the empirical analysis, we try both D1 and D2 as measures of being potential borrowing constrained. We report the results from using the basic split,

\footnotetext{
${ }^{15}$ Until a credit market reform in 1992 , it was not possible to use the proceeds from mortgage loans for other purposes than financing real property.
} 
D1, as this turns out to be statistically more significant than D2.

\section{Empirical Results}

Our discussion of the results follows our discussion of our empirical approach in Section 5 very closely. The first specification is analogous to the simple difference-in-differences approach described in equation (3) above. These results are presented in the first three columns of Table 6 for the full group, men, and women. Note that we do not present the probit coefficients but rather the average derivates so that the results are interpretable. One can see from the table that the effects are statistically significant and that the magnitude is larger for women than it is for men. ${ }^{16}$ The stipend is defined as the fraction of the full stipend. That is an individual would have a value of $S_{i}=1$ if they were eligible for the full stipend. Since the full stipend represents approximatley $\$ 6,000$ per year the coefficient implies that the effect of a $\$ 1,000$ subsidy would be to change enrollment by $1.35 \%$ and the confidence interval around this value is tight. This is a substantially smaller effect than the magnitude typically found in the U.S.

Our next goal is to account for borrowing constraints by taking advantage of the kink in the subsidy amount. In particular we implement the idea in specification (4) by controlling for a linear term in specifications (4)-(6) and a quadratic term in specification (7). One can see the basic result most clearly in column (4). The point estimates work as one might expect. The coefficient on the interaction between income percentile and the reform is negative which implies that the reform has a stronger effect on students from poorer families. Further this leads the coefficient on the stipend to increase substantially although the overall effect is still quite small compared to the previous literature. However, note that the key interaction term is not statistically significant and the estimate of the main effect (coefficient on Stipend) has become considerably less precise. The coefficient on Stipend is still statistically significant, but the confidence interval now includes considerably higher values. In column (7) we include a squared term (i.e. $g(\cdot)$ in (4) is now quadradic rather than linear). One can see that the point estimate changes very little although we lose a bit of precision. In terms of borrowing constraints, the fact that the coefficient on the interaction between income percentile and the reform is not significant means that we find no evidence of them. However, it is not clear

\footnotetext{
${ }^{16}$ The results from this specification is in accordance with the findings by Angrist, Lang and Oreopoulos (2007).
} 
at all whether this is due to small effects or lack of power. Perhaps the main advantage of the structural model to follow is that it helps to answer this question. The main thing we learn from this exercise about the main effect is not clear. The point estimate increased, but the standard errors did as well. In order to get more precise estimates we turn to our second method for dealing with borrowing constraints.

We first estimate the highly interacted model (6) in Table 7. The point estimates go the opposite of what one would expect. The coefficient on the interaction between the stipend and the low asset indicator is actually negative suggesting that the stipend actually has a smaller effect on those likely to be borrowing constrained rather than a positive effect as one might expect. However, this negative interaction is not statistically significant. Once again the results suggest relatively small effects of the subsidy (that is relative to the previous literature) and also suggest that borrowing constraints do not appear to be important.

The specification (7) is presented in Table 8 and is closer to what the model predicts. We find a marginal effect of 0.095 overall for the non-borrowing constrained individuals. The effect for borrowing constrained individuals can be seen from the interaction between the stipend and low assets as well as the interaction between the stipend, low assets, and family income. For low liquid asset/low income families the effect of the stipend is substantially higher. For example, for a low asset family at the tenth income percentile the effect is

$$
0.095+0.086-0.125 \times 0.1=0.181
$$

which is substantially larger than the main result. To get a better sense of whether these effects are large or not, we use our structural model.

The structural model is a nonlinear probit model represented in equation (9) and estimation by maximum likelihood is straightforward. We estimate the model assuming that students from families with low liquid asset holdings are potentially borrowing constrained. In doing so, we control for family income, the interaction between family income and low liquid assets, and for graduation cohorts. In this sense, identification is analogous to the difference-in-differences models presented above. The results from the structural model are presented in Table 9. While not guaranteed, one can see that the $1 / \sigma_{\varepsilon}$ parameter is positive and statistically significant. Looking at the form of the probit model above, this results because our prediction of $V_{1 i}-V_{0 i}$ does predict college enrollment. This is the key parameter in the model, and we find it to be generally robust across different specifications of the model. 
The main advantage of estimating the strucutural model is that we can use it to simulate various policy counterfactuals. In Table 10 we present results that conform to two different types of simulations. The first involves relaxing borrowing constraints while the second involves changing the subsidy level. The middle row in Table 10 corresponds to the current subsidy level. Looking at the columns to the right one can see that relaxing the borrowing constraint would lead to only a slight increase in college going rates. Even for the low income potentially constrained, eliminating the constraint would only increase education levels from $33.2 \%$ to $33.6 \%$. However, the subsidy itself is important. Completely eliminating the subsidy would reduce enrollment among all groups by more than 7 percentage points. One should of course keep in mind that this is a very large subsidy so this is not surprising. ${ }^{17}$. This effect is a little smaller than the effects estimated in the reduced form analysis and substantially smaller than the ones estimated in the previous literature. An interesting result is the importance of the borrowing constraint in the absence of the subsidy. In this case, eliminating borrowing constraints would raise education levels for the low income potentially constrained from $25.5 \%$ to $27 \%$. This is a large effect relative to the enrollment rate and relative to the change for the current subsidy level, but it is still not huge.

One can also see in Table 10 that if we were to double the stipend one would see a substantial increase in enrollment for all groups and a complete elimination of the importance of borrowing constraints.

\subsection{Analysis of capacity constraints}

The effect of a change in demand on the observed quantity depends crucially on the supply side (that is the number of openings for students throughout the country). This is also the case in the market for education. To derive the change in demand from changes in observed college enrollment and attainment, we need to know something about the supply side of the educational market or at least make our results conditional on assumptions about supply. The existing literature have, most often, implicitly, assumed a totally flexible supply of education, thereby equating demand changes to observed changes in quantities. This approach seems reasonable when studying effects on a limited subset of the population, but when whole cohorts are affected, as in our case, the supply of education might no longer

\footnotetext{
${ }^{17}$ The yearly stipend corresponds to 48,968 DKK (2001 prices) or approximately $\$ 6,000$ US dollars using the exchange rate at that time.
} 
adjust fully to match the increased demand.

Generally, if supply is not perfectly elastic, an increase in demand would lead to price increases. In the Danish educational system, however, education is publicly provided, so there are no direct price mechanism in the educational sector to observe. Thus, we need another observable variable to somehow gauge the elasticity or flexibility of the supply. When the demand for a particular education exceeds the study places supplied, the applicants are to a large extent sorted by their high school GPA. ${ }^{18}$ When the net return to education increases, we would expect the demand for education to increase for high school graduates with low as well as high GPA. If the supply is totally elastic and follows demand, the composition of those being induced to take further education determines whether the average GPA of enrolled students goes up or down. However, if the supply is fixed we would expect the average GPA of enrolled students to increase, as GPA is the main sorting instrument.

In Figure 3, which is based on a gross data set for a longer time period, we plot the average high school GPA of first-year students for all colleges and for university college. We do not see an unambiguous effect of the reform on the average GPA of enrolled students, but there seem to be a upward trend from 1984 with a slight drop in 1988 and a jump afterwards. This observation might indicate an increased excess demand for education, and, therefore, a wedge between the increase in demand and the increase in actual enrollment. However, the increased average GPA of enrolled students in Figure 3 might just be a result of a timevarying distribution of high school GPA as indicated by Tabel 3. To accommodate this potential problem, we normalize each student's GPA by the average in his or her high school cohort. Still, the figures are vulnerable to changes in other moments in the distribution of high school GPA. In Figure 4 we plot the averages of these relative GPAs for first-year students. Now the series seem more stationary - though, still with a slight drop in 1988 and a jump up in 1989 - indicating that the increased enrollment following the reform was not to a considerably extent dampened by an inflexible supply. To conclude, potential supply constraints do not seem to have changed the composition of enrolled students with respect to high school GPA. This analysis is, of course, not perfectly capable of identifying the elasticity of the supply, but with these figures in mind, we are more confident in directly linking changes in observed enrollment to changes in demand for education.

\footnotetext{
${ }^{18} \mathrm{~A}$ (varying) fraction of the study places are reserved for so called second-quota-applicants, who can supplement their GPA with e.g. work experience, folk high school.
} 


\section{Conclusion}

Empirical studies across time and countries find a strong intergenerational correlation in schooling, and more generally a strong relationship between family background and schooling. To make the educational attainment less dependent of the parental background, educational subsidies which are means-tested against parental income have been introduced all over the world. We devote this paper to study how those subsidies influence the demand for college education.

From a reduced form analysis taking potential borrowing constraints into account, we find that college enrollment increases with increasing subsidy. A $\$ 1,000$ increase in the stipend increases college enrollment by 1.35 percentage points, which is a somewhat lower response than found in the earlier literature. One reason might be that large subsidies are already in place. Introducing a simple structural model allows us to simulate different

policy counterfactuals. These exercises show that borrowing constraints do not appear to be particularly important in Denmark at this time.

\section{A Appendix: A regression kink design}

We control for the parents' financial situation by including their position in the income distribution. If we believe that, for instance, borrowing constraints play a significant role in the schooling decision it would be misleading to restrict the responsiveness of stipend to be constant across individuals. The variation in stipend over time is a direct function of parental income, and therefore, strong functional form assumptions are needed to allow the responsiveness to stipend to vary across income. However, the means-testing algorithm provides us with a kink in the relationship between parents' income and the grant eligible for. This kink could be exploited for non-parametric identification.

Consider the following general specification in which $Y_{i}$ represents a generic dependent variable,

$$
Y_{i}=g\left(X_{i}, S_{i}\right)+u_{i}
$$

where $X_{i}$ is a continuous variable and $S_{i}$ is the treatment variable which we treat as continuous here. The main issue for identification is that $S_{i}$ is completely determined by $X_{i}$ (i.e. $\left.S_{i}=S\left(X_{i}\right)\right)$. The standard problem one faces in this type of analysis is that $u_{i}$ is correlated 
with $X_{i}$ (and thus $S_{i}$ ). However, suppose that there is a kink in the function $S$ at some value $x^{*}$, but not in the function $g\left(X_{i}, \cdot\right)$ or the function $E\left(u_{i} \mid X_{i}\right)$. To simplify, we assume that $g\left(X_{i}, \cdot\right)$ and $E\left(u_{i} \mid X_{i}\right)$ are continuous differentiable. Define $d_{0}$ and $d_{1}$ such that

$$
\begin{aligned}
d_{0} & \equiv \lim _{x \uparrow x^{*}} \frac{\partial S(x)}{\partial x} \\
d_{1} & \equiv \lim _{x \downarrow x^{*}} \frac{\partial S(x)}{\partial x}
\end{aligned}
$$

Then

$$
\begin{aligned}
& \frac{\lim _{x \downarrow x^{*}} \frac{\partial E\left(Y_{i} \mid X_{i}=x\right)}{\partial x}-\lim _{x \uparrow x^{*}} \frac{\partial E\left(Y_{i} \mid X_{i}=x\right)}{\partial x}}{d_{1}-d_{0}} \\
& =\frac{\lim _{x \downarrow x^{*}}\left(\frac{\partial g(x, S(x))}{\partial x}+\frac{\partial g(x, S(x))}{\partial s} \frac{\partial S(x)}{\partial x}+\frac{\partial E\left(u_{i} \mid X_{i}=x\right)}{\partial x}\right)}{d_{1}-d_{0}} \\
& -\frac{\lim _{x \uparrow x^{*}}\left(\frac{\partial g(x, S(x))}{\partial x}+\frac{\partial g(x, S(x))}{\partial s} \frac{\partial S(x)}{\partial x}+\frac{\partial E\left(u_{i} \mid X_{i}=x\right)}{\partial x}\right)}{d_{1}-d_{0}} \\
& =\frac{\frac{\partial g\left(x^{*}, S\left(x^{*}\right)\right)}{\partial x}+\frac{\partial g\left(x^{*}, S\left(x^{*}\right)\right)}{\partial s} d_{1}+\frac{\partial E\left(u_{i} \mid X_{i}=x^{*}\right)}{\partial x}}{d_{1}-d_{0}} \\
& \frac{-\frac{\partial g\left(x^{*}, S\left(x^{*}\right)\right)}{\partial x}-\frac{\partial g\left(x^{*}, S\left(x^{*}\right)\right)}{\partial s} d_{0}-\frac{\partial E\left(u_{i} \mid X_{i}=x^{*}\right)}{\partial x}}{d_{1}-d_{0}} \\
& =\frac{\partial g\left(x^{*}, S\left(x^{*}\right)\right)}{\partial s}
\end{aligned}
$$

Hence, this treatment effect is nonparametrically identified at the kink points. In practice, one must use more parameterized models to obtain reasonable precision. But still, the difference in sensitivity to income changes between those just to the left of the kink point and those just to the right of it, can provide identification. Thus, theoretically, the treatment effect is identified even when we allow the effect of parental income to be different after the reform. This assumes, of course, that the kink points are known and that they are exogenous to income formation. In practice, data will determine whether we have sufficient power to separate $S_{i}$ from parental income $X_{i}$. This approach resembles the regression discontinuity idea. Instead of a discontinuity of in the level of the stipend-income function, we have a discontinuity in the slope of the function. Rothstein and Rouse (2007) apply a similar approach in estimating the effect of student debt on post-graduation behavior. 


\section{References}

[1] Angrist, J., K. Lang, and P. Oreopoulos (2007), Incentives and Services for College Achievement: Evidence from a Randomized Trial, IZA DP \#3134. IZA, Bonn.

[2] Arendt, J. N. (2008), The Impact of Public Student Grants on Drop-out and Completion of Higher Education - Evidence from a Student Grant Reform. HE Paper 2008:10. University of Southern Denmark.

[3] Baumgartner, H. J. and V. Steiner (2006), Does More Generous Student Aid Increase Enrolment Into Higher Education? Evaluating the German Student Aid Reform of 2001, IZA DP No. 2034.

[4] Becker, G. S. and N. Tomes (1986), Human Capital and the Rise and Fall of Families, Journal of Labor Econmics 4: S1-S39.

[5] Belley, P., and L. Lochner (2007), The Changing Role of Family Income and Ability in Determining Educational Achievement, Journal of Human Capital, vol1. 1, no. 1, 37-89

[6] Blundell, R. A. Duncan, and C. Meghir (1998), Estimating Labor Supply Responses Using Tax Reforms, Econometrica 66: 827-861.

[7] Brown, M., J.K. Sholz, and A. Seshadri (2007), "A New Test of Borrowing Constraints for Education," unpublished manuscript, University of Wisconsin-Madison.

[8] Cameron, S. and C. Taber (2004), Estimation of Educational Borrowing Constraints Using Returns to Schooling, Journal of Political Economy 112: 132-182.

[9] Carneiro, P. and J. J. Heckman (2002), The Evidence on Credit Constraints in Postsecondary Schooling, Economic Journal 112: 705-734.

[10] Card, D. (1999), The Causal Effect of Education on Earnings, in Handbook of Labor Economics vol. 3A, edited by O. Ashenfelter and D. Card. Amsterdam: Elsevier.

[11] Card, D. (2001), Estimating the Returns to Schooling: Progress n Some Persistent Econometric Problems, Econometrica 69: 1127-60.

[12] Danish Educational Support Agency (2000), "Studerende i SU-uddannelse: Støtte og studiemæssig adfærd 1989-1997." (In English: Students eligible for State Education Grants: Support and Behaviour). Report, SU Analyse.

[13] Dynarski, S. (2003), Does Aid Matter? Measuring the Effect of Student Aid on College Attendance and Completion, American Economic Review 93: 279-288.

[14] Dynarski, S. (2000), Hope for Whom? Financial Aid for the Middle Class and Its Impact on College Attendace, National Tax Journal, 53: 629-661.

[15] Hansen, W. (1983). Impact of student financial aid on access. In Joseph Froomkin (Ed.). The crisis in higher education. New York: Academy of Political Science.

[16] Heckman, J. J., L. Lochner and C. Taber (1998), General Equilibrium Treatment Effects: A Study of Tuition Policy, American Economic Review, 88: 381-386.

[17] Joensen, J. S. (2008), Academic and Labor Market Success: The Impact of Student Employment, Abilities, and Preferences. Manuscript, Stockholm School of Economics. 
[18] Kane, T. (1995), Rising Public College Tuition and College Entry: How Well do Public Subsidies Promote Access to College?, NBER WP No. 5164.

[19] Keane, M. P. and K. I. Wolpin (2001), The Effect of Parental Transfers and Borrowing Constraints on Educational Attainment, Internatinal Economic Review 42: 1051-1103.

[20] Leslie, L. and P. Brinkman (1988), The Economic Value of Higher Education, New York: Macmillian.

[21] Leth-Petersen, S. (2006), Intertemporal Consumption and Credit Constraints: Does Total Expenditure Respond to An Exogenous Shock to Credit? Manuscript, U of Copenhagen, Denmark.

[22] Linsenmeier, D. S., H. S. Rosen and C. E. Rouse (2006), Financial Aid Packages and College Enrolment Decisions: An Econometric Case Study, Review of Economics and Statistics 88:126-145.

[23] McPherson, M. S. and M. O. Schapiro (1991), Does Student Aid Affect College Enrolment? New Evidence on a Persistent Controversy, American Economic Review 81: 309-318.

[24] Rothstein, J. and C. Rouse (2007), Constrained After College: Student Loans and Early Career Occopational Choices, Unpublished working paper

[25] Seftor, N. S. and S. E. Turner (2002), Back to school: Federal Student Aid Policy and Adult College Enrolment, The Journal of Human Resources37: 336-352.

[26] Shea, J. (2000), Does Parents' Money Matter?, Journal of Public Economics 77: 155-84.

[27] Shin, J.-C. and S. Milton (2006), Rethinking Tuition Effects on Enrolment in Public Four-Year Colleges and Universities, The Review of Higher Education 29:213-237.

[28] Stinebrickner, T. and R. Stinebrickner (2009), "The Effect of Credit Constraints on the College Drop-Out Decision: A Direct Approach Using a New Panel Study," forthcoming American Economic Review.

[29] Turner, S. E. (1998), The Vision and Reality of Pell Grants: Unforeseen Consequences for Students and Institutions. In L. Gladieux (Ed) Memory, Reason, Imagination: A Quarter Century of Pell Grants. Washington, D.C.: College Board.

[30] Van der Klaauw, W. (2002), Estimating the Effect of Financial Aid Offers on College Enrolment: A Regression-Discontinuity Approach, International Economic Review 43: 1249-1287.

[31] Zeldes, S. P. (1989), Consumption and Liquidity Constraints: An Empirical Investigation, Journal of Political Economy 97: 305-346. 
Table 1

Overview of higher education programmes in Denmark

\begin{tabular}{lll}
\hline \hline $\begin{array}{l}\text { Educational } \\
\text { category }\end{array}$ & Length & Examples \\
\hline $\begin{array}{l}\text { Short-cycle } \\
\text { higher edu- } \\
\text { cation }\end{array}$ & 2 years & $\begin{array}{l}\text { The fields of study include agriculture, textile and de- } \\
\text { sign, food industry, construction, hotel and tourism, } \\
\text { computer programming, industrial production, labora- } \\
\text { tory technician, IT and communication and interna- } \\
\text { tional marketing. }\end{array}$ \\
\hline $\begin{array}{l}\text { Mediumcycle } \\
\text { higher edu- } \\
\text { cation }\end{array}$ & & $\begin{array}{l}\text { Professional programmes like teacher training pro- } \\
\text { grammes, programmes in social work, journalism, nurs- } \\
\text { ing, engineering etc. and research-based Bachelor pro- } \\
\text { grammes. }\end{array}$ \\
\hline $\begin{array}{l}\text { Long-cycle } \\
\text { higher edu- } \\
\text { cation }\end{array}$ & 5 to 6 years & $\begin{array}{l}\text { The master programmes. The programmes qualify stu- } \\
\text { dents for occupational functions and scientific work. }\end{array}$ \\
\hline
\end{tabular}

Table 2

College Enrollment, Year X After Graduation

\begin{tabular}{cccccccc}
\hline \hline $\begin{array}{c}\text { High school } \\
\text { graduation cohort }\end{array}$ & Year 0 & Year 1 & Year 2 & Year 3 & Year 4 & Year 5 & Nobs \\
\hline 1983 & 0.206 & 0.407 & 0.548 & 0.636 & 0.683 & 0.709 & 12,710 \\
1984 & 0.192 & 0.379 & 0.528 & 0.612 & 0.667 & 0.695 & 14,028 \\
1985 & 0.160 & 0.363 & 0.522 & 0.617 & 0.664 & 0.692 & 14,686 \\
1986 & 0.153 & 0.358 & 0.528 & 0.621 & 0.672 & 0.700 & 14,328 \\
1987 & 0.144 & 0.365 & 0.542 & 0.649 & 0.703 & 0.732 & 13,008 \\
1988 & 0.144 & 0.368 & 0.559 & 0.667 & 0.721 & 0.753 & 12,798 \\
1989 & 0.159 & 0.431 & 0.612 & 0.701 & 0.752 & 0.781 & 13,119 \\
1990 & 0.188 & 0.451 & 0.617 & 0.710 & 0.759 & 0.788 & 14,256 \\
\hline All cohorts & 0.168 & 0.390 & 0.557 & 0.652 & 0.702 & 0.730 & 108,933 \\
\hline
\end{tabular}


Table 3

Means of Central Variables by High School Graduation Cohort

\begin{tabular}{|c|c|c|c|c|c|}
\hline & \multicolumn{4}{|c|}{ "High school graduation cohort } \\
\hline & & 1985 & 1986 & 1987 & 1988 \\
\hline \multicolumn{2}{|l|}{ High school graduation age (years) } & 19.29 & 19.33 & 19.35 & 19.35 \\
\hline \multicolumn{2}{|l|}{ Male } & 0.411 & 0.397 & 0.413 & 0.409 \\
\hline \multicolumn{2}{|l|}{ GPA } & 8.01 & 8.06 & 8.10 & 8.15 \\
\hline \multicolumn{2}{|l|}{ Mothers education category 0 (basic school) } & 0.359 & 0.336 & 0.312 & 0.298 \\
\hline \multicolumn{2}{|c|}{ Mothers education cat. 1 (high school or similar) } & 0.016 & 0.016 & 0.017 & 0.018 \\
\hline \multicolumn{2}{|c|}{ Mothers education cat. 2 (vocational education) } & 0.366 & 0.382 & 0.382 & 0.386 \\
\hline \multicolumn{2}{|c|}{ Mothers education cat. 3 (short cycle higher education) } & 0.043 & 0.042 & 0.046 & 0.045 \\
\hline \multicolumn{2}{|c|}{ Mothers education cat. 4 (medium cycle higher education) } & 0.192 & 0.198 & 0.216 & 0.222 \\
\hline \multicolumn{2}{|c|}{ Mothers education cat. 5 (long cycle higher education) } & 0.025 & 0.026 & 0.028 & 0.031 \\
\hline \multicolumn{2}{|c|}{ Fathers education cat. 0 (basic school) } & 0.250 & 0.243 & 0.233 & 0.222 \\
\hline \multicolumn{2}{|c|}{ Fathers education cat. 1 (high school or similar) } & 0.019 & 0.018 & 0.021 & 0.022 \\
\hline \multicolumn{2}{|c|}{ Fathers education cat. 2 (vocational education) } & 0.400 & 0.403 & 0.389 & 0.390 \\
\hline \multicolumn{2}{|c|}{ Fathers education cat. 3 (short cycle higher education) } & 0.043 & 0.044 & 0.049 & 0.048 \\
\hline \multicolumn{2}{|c|}{ Fathers education cat. 4 (medium cycle higher education) } & 0.176 & 0.178 & 0.189 & 0.191 \\
\hline \multicolumn{2}{|c|}{ Fathers education cat. 5 (long cycle higher education) } & 0.111 & 0.114 & 0.119 & 0.127 \\
\hline \multicolumn{2}{|c|}{ Living in a large municipality (excluding the four largest) } & 0.339 & 0.338 & 0.334 & 0.335 \\
\hline \multicolumn{2}{|c|}{ Living in one of the four largest municipalities } & 0.313 & 0.306 & 0.300 & 0.290 \\
\hline \multicolumn{2}{|c|}{ D1: Parents' liquid assets less than one month's income* } & 0.280 & 0.298 & 0.284 & \\
\hline \multicolumn{2}{|c|}{ D2: Parents' liquid assets less than two month's income* } & 0.391 & 0.399 & 0.385 & 0.29 \\
\hline \multicolumn{2}{|c|}{ At least one of the parents are self-employed $(0 / 1)$} & 0.215 & 0.219 & 0.209 & 0.227 \\
\hline \multicolumn{2}{|c|}{ Number of observations } & 14,686 & 14,328 & 13,00 & 12,79 \\
\hline \multicolumn{6}{|l|}{$*$ If parents are self-employed we impose $\mathrm{D}=0$} \\
\hline \multicolumn{6}{|c|}{$\begin{array}{c}\text { Table } 4 \\
\text { Portfolio Composition by High School Graduation Cohort }\end{array}$} \\
\hline & \multicolumn{5}{|c|}{ "High school graduation cohort } \\
\hline Average proportion of portfolio in & 19851986 & 1987 & 1988 & 1989 & 1990 \\
\hline Cash & 0.264 & 0.281 & 0.316 & 0.273 & 0.268 \\
\hline Other & 0.524 & 0.504 & 0.398 & 0.455 & 0.474 \\
\hline Mortgage deeds & 0.068 & 0.058 & 0.066 & 0.059 & 0.054 \\
\hline Bonds & 0.079 & 0.065 & 0.099 & 0.092 & 0.083 \\
\hline Shares & 0.056 & 0.095 & 0.121 & 0.121 & 0.121 \\
\hline Total & 1.000 & 1.000 & 1.000 & 1.000 & 1.000 \\
\hline & 1985 & 1987 & 1988 & 1989 & 1990 \\
\hline D1 & 0.298 & 0.284 & 0.189 & 0.211 & 0.248 \\
\hline D2 & 0.391 & 0.385 & 0.296 & 0.332 & 0.368 \\
\hline
\end{tabular}


Table 5

Portfolio Composition by Low Liquid Asset Split: Basic vs. Extreme

\begin{tabular}{lcccc}
\hline \hline & \multicolumn{4}{c}{ Low liquid asset split } \\
& \multicolumn{3}{c}{ Basic } & \multicolumn{2}{c}{ Extreme } \\
\hline Average proportion of portfolio in & D1=1 & D1=0 & D2=1 & D2 $=0$ \\
\hline Cash & 0.097 & 0.338 & 0.174 & 0.340 \\
Other & 0.832 & 0.363 & 0.724 & 0.334 \\
Mortgage deeds & 0.012 & 0.080 & 0.024 & 0.086 \\
Bonds & 0.014 & 0.104 & 0.024 & 0.115 \\
Shares & 0.045 & 0.116 & 0.054 & 0.125 \\
\hline Total & 1.000 & 1.000 & 1.000 & 1.000 \\
\hline Number of students with observed liquid assets of parents & 17,576 & 56,102 & 26,626 & 47,052 \\
\hline
\end{tabular}

Table 6

Probit Model for College Enrollment, Cohorts 1985, 1988-1990 Marginal Effects on College Enrollment

(Standard Errors in Parentheses)

\begin{tabular}{lccccccc}
\hline \hline & $(1)$ & $(2)$ & $(3)$ & $(4)$ & $(5)$ & $(6)$ & $(7)$ \\
\hline Stipend & All & Men & Women & All & Men & Women & All \\
& 0.082 & 0.064 & 0.106 & 0.143 & 0.160 & 0.118 & 0.146 \\
Income Percentile & $(0.017)$ & $(0.028)$ & $(0.021)$ & $(0.043)$ & $(0.068)$ & $(0.054)$ & $(0.051)$ \\
& 0.043 & 0.067 & 0.026 & 0.067 & 0.105 & 0.030 & -0.009 \\
& $(0.017)$ & $(0.027)$ & $(0.022)$ & $(0.023)$ & $(0.037)$ & $(0.030)$ & $(0.060)$ \\
Income Percentile Squared & & & & & & & 0.056 \\
& & & & & & & $(0.041)$ \\
Pre-Reform Stipend & -0.005 & 0.061 & -0.055 & -0.036 & 0.012 & -0.061 & -0.070 \\
& $(0.025)$ & $(0.041)$ & $(0.032)$ & $(0.032)$ & $(0.052)$ & $(0.040)$ & $(0.039)$ \\
Income Percentile $\times$ Reform Dummy & & & & -0.049 & -0.076 & -0.009 & -0.055 \\
& & & & $(0.031)$ & $(0.049)$ & $(0.040)$ & $(0.082)$ \\
Income Percentile Squared & & & & & & & 0.005 \\
$\times$ Reform Dummy & & & & & & & $(0.057)$ \\
High School GPA included & yes & yes & yes & yes & yes & yes & yes \\
Sex, age and geographical indicators & yes & yes & yes & yes & yes & yes & yes \\
Indicators for graduation cohort & yes & yes & yes & yes & yes & yes & yes \\
Controls for parents' education & yes & yes & yes & yes & yes & yes & yes \\
Log-likelihood & -48967 & -20205 & -28663 & -48965 & -20203 & -28663 & -48964 \\
\hline Number of observations & 81,581 & 33,383 & 48,198 & 81,581 & 33,383 & 48,198 & 81,581 \\
\hline
\end{tabular}




\section{Table 7}

Probit Model for College Enrollment With Controls for Borrowing Constraints Cohorts 1985, 1988-1990

Marginal Effects on College Enrollment (Standard Errors in Parentheses)

\begin{tabular}{lc}
\hline \hline & $(1)$ \\
\hline Stipend & 0.114 \\
Income Percentile & $(0.032)$ \\
& 0.037 \\
Pre-Reform Stipend & $(0.022)$ \\
& -0.011 \\
Low assets (0/1) & $(0.030)$ \\
& 0.027 \\
Stipend $\times$ Low assets & $(0.027)$ \\
& -0.077 \\
Reform $\times$ Low assets & $(0.049)$ \\
& 0.049 \\
Income Percentile $\times$ Low assets & $(0.032)$ \\
High School GPA included & -0.017 \\
Sex, age and geographical indicators included & $(0.020)$ \\
Indicators for graduation cohort included & yes \\
Controls for parents' education included & yes \\
Include self-employed & yes \\
Log-likelihood & yes \\
\hline Number of observations & yes \\
\hline
\end{tabular}


Table 8

Probit Model for College Enrollment, Cohorts 1985, 1988-1990

Marginal Effects on College Enrollment (Standard Errors in Parentheses)

\begin{tabular}{|c|c|c|c|}
\hline & $\begin{array}{l}(1) \\
\text { All } \\
\end{array}$ & $\begin{array}{c}(2) \\
\text { Men } \\
\end{array}$ & $\begin{array}{c}(3) \\
\text { Women }\end{array}$ \\
\hline Stipend & $\begin{array}{c}0.095 \\
(0.026)\end{array}$ & $\begin{array}{c}0.113 \\
(0.042)\end{array}$ & $\begin{array}{c}0.092 \\
(0.033)\end{array}$ \\
\hline Income Percentile & $\begin{array}{c}0.033 \\
(0.021)\end{array}$ & $\begin{array}{c}0.037 \\
(0.033)\end{array}$ & $\begin{array}{c}0.029 \\
(0.027)\end{array}$ \\
\hline Pre-Reform Stipend & $\begin{array}{l}-0.022 \\
(0.030)\end{array}$ & $\begin{array}{c}0.019 \\
(0.049)\end{array}$ & $\begin{array}{l}-0.050 \\
(0.038)\end{array}$ \\
\hline Low assets $(0 / 1)$ & $\begin{array}{c}-0.074 \\
(0.042)\end{array}$ & $\begin{array}{l}-0.157 \\
(0.065)\end{array}$ & $\begin{array}{l}-0.015 \\
(0.055)\end{array}$ \\
\hline Stipend $\times$ Low assets & $\begin{array}{c}0.086 \\
(0.038)\end{array}$ & $\begin{array}{c}0.168 \\
(0.077)\end{array}$ & $\begin{array}{c}0.024 \\
(0.061)\end{array}$ \\
\hline Stipend $\times$ Income Percentile $\times$ Low assets & $\begin{array}{l}-0.125 \\
(0.060)\end{array}$ & $\begin{array}{c}-0.283 \\
(0.111)\end{array}$ & $\begin{array}{l}-0.003 \\
(0.090)\end{array}$ \\
\hline Income Percentile $\times$ Low assets & $\begin{array}{c}0.087 \\
(0.062)\end{array}$ & $\begin{array}{c}0.241 \\
(0.097)\end{array}$ & $\begin{array}{l}-0.029 \\
(0.079)\end{array}$ \\
\hline High School GPA included & yes & yes & yes \\
\hline Sex, age and geographical indicators included & yes & yes & yes \\
\hline Indicators for graduation cohort included & yes & yes & yes \\
\hline Controls for parents' education included & yes & yes & yes \\
\hline Log-likelihood & $-32,613$ & $-13,391$ & $-19,161$ \\
\hline Number of observations & 54,843 & 22,438 & 32,405 \\
\hline
\end{tabular}




\section{Table 9}

Estimates From Structural Model

(Standard Errors in Parentheses )

\begin{tabular}{|c|c|}
\hline $\begin{array}{l}\text { Variable } \\
\frac{1}{\sigma_{\varepsilon}}\end{array}$ & $\begin{array}{c}4.346 \\
(1.463)\end{array}$ \\
\hline \multicolumn{2}{|c|}{ Parameters determining $f_{i}$ (i.e. $\gamma$ ) } \\
\hline Intercept & $\begin{array}{c}6.801 \\
(3.238)\end{array}$ \\
\hline Family Income & $\begin{array}{c}1.584 \\
(4.941)\end{array}$ \\
\hline \multicolumn{2}{|c|}{ Taste Parameters (i.e. $\theta$ ) } \\
\hline Intercept & $\begin{array}{l}-4.891 \\
(0.299)\end{array}$ \\
\hline Pre-reform Stipend & $\begin{array}{l}-0.031 \\
(0.078)\end{array}$ \\
\hline Family Income & $\begin{array}{c}0.109 \\
(0.076)\end{array}$ \\
\hline Low Assets & $\begin{array}{c}0.015 \\
(0.088)\end{array}$ \\
\hline Lows Assets $\times$ Family Income & $\begin{array}{l}-0.068 \\
(0.120)\end{array}$ \\
\hline GPA & $\begin{array}{c}0.501 \\
(0.006)\end{array}$ \\
\hline Male & $\begin{array}{c}0.184 \\
(0.012)\end{array}$ \\
\hline Age 19 at HS Graduation & $\begin{array}{c}0.002 \\
(0.014)\end{array}$ \\
\hline Parent's Education Dummies & Yes \\
\hline Geographical Indicators & Yes \\
\hline Indicators for graduation cohort & Yes \\
\hline Mean log-likelihood & -0.594702 \\
\hline
\end{tabular}

Table 10

Policy Simulations From Structural Model

\begin{tabular}{lccc|ccc}
\hline \hline & \multicolumn{3}{c}{ Enrollment rates } & \multicolumn{3}{c}{ Effect of removing constraints } \\
\cline { 2 - 7 } & High Assets & \multicolumn{2}{c}{ Low Assets } & \multicolumn{3}{c}{ Low Assets } \\
No stipend & 0.356 & Low Inc. & High Inc. & All & Low Inc. & High Inc. \\
Actual stipend & 0.427 & 0.332 & 0.395 & 0.009 & 0.015 & 0.003 \\
Double stipend & 0.499 & 0.406 & 0.541 & 0.002 & 0.004 & 0.000 \\
& & & 0.000 & 0.000 & 0.000
\end{tabular}




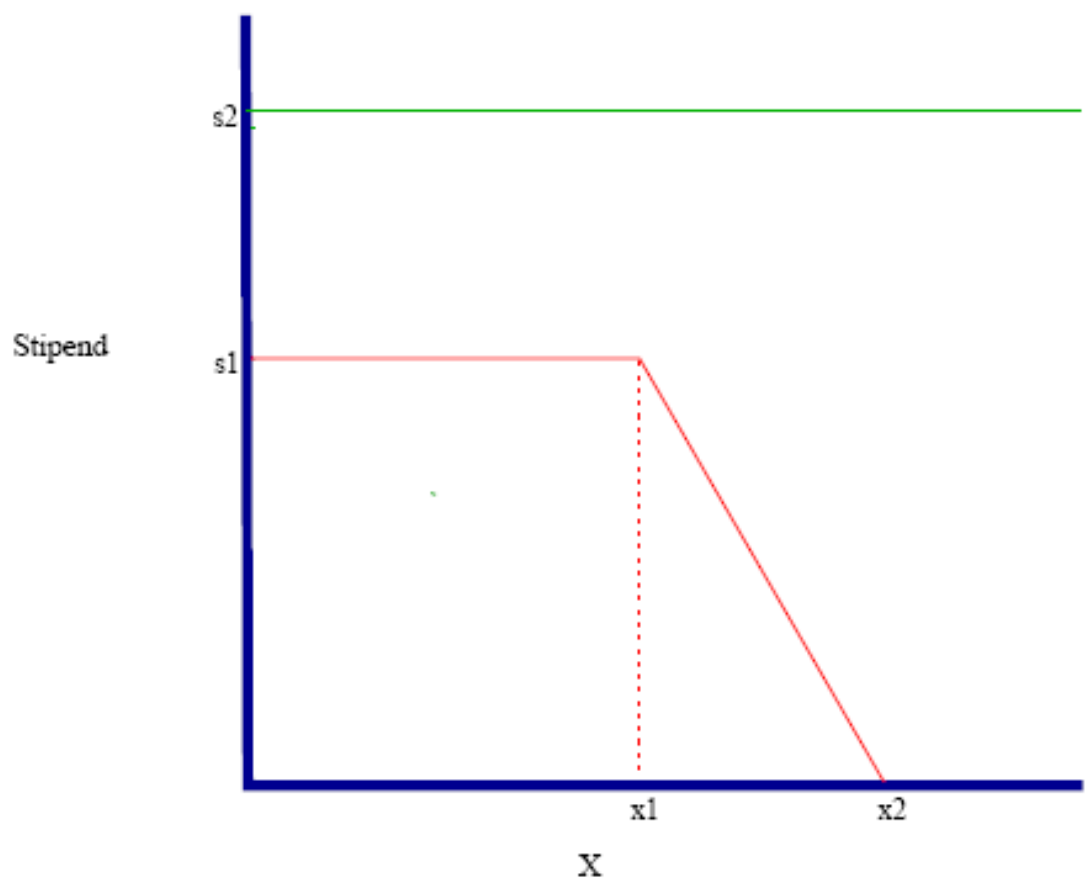

Figure 1: Illustration of the influence of the reform on the stipend. 


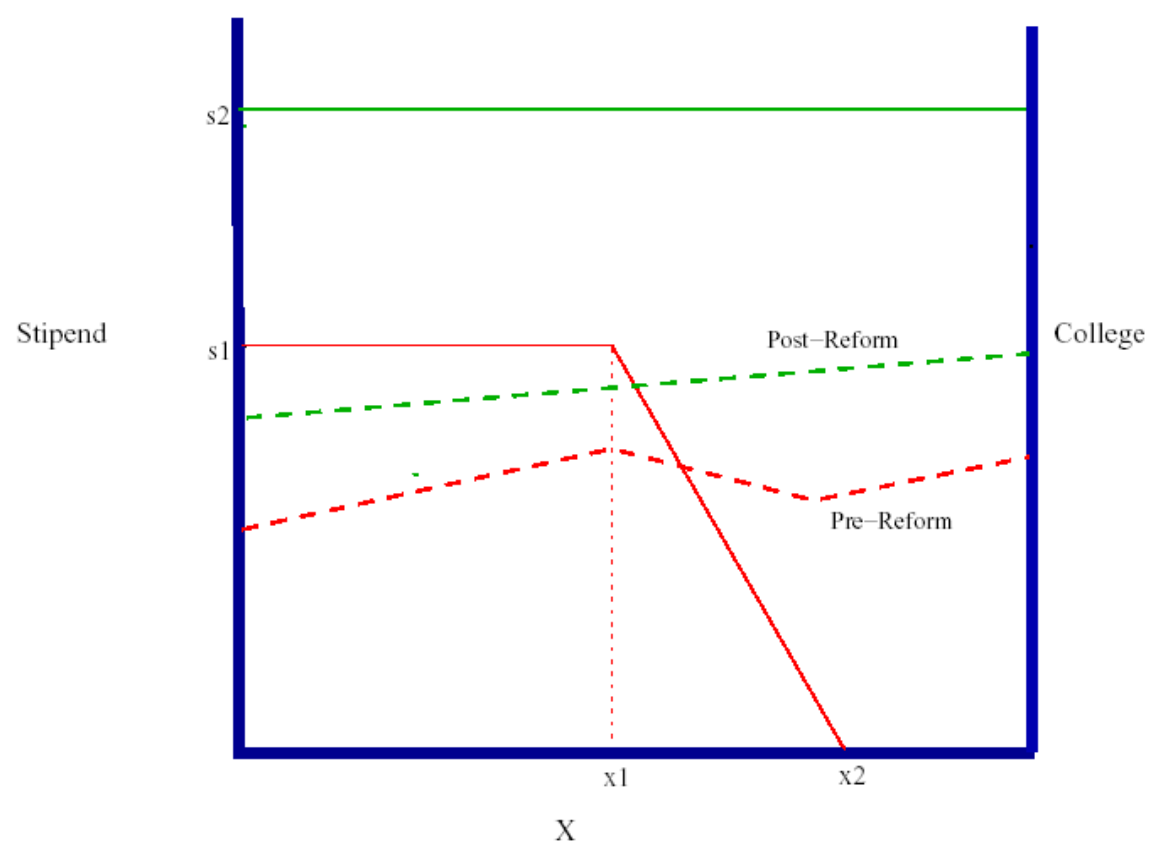

Figure 2: The stipend rule and it's relation to enrollment.

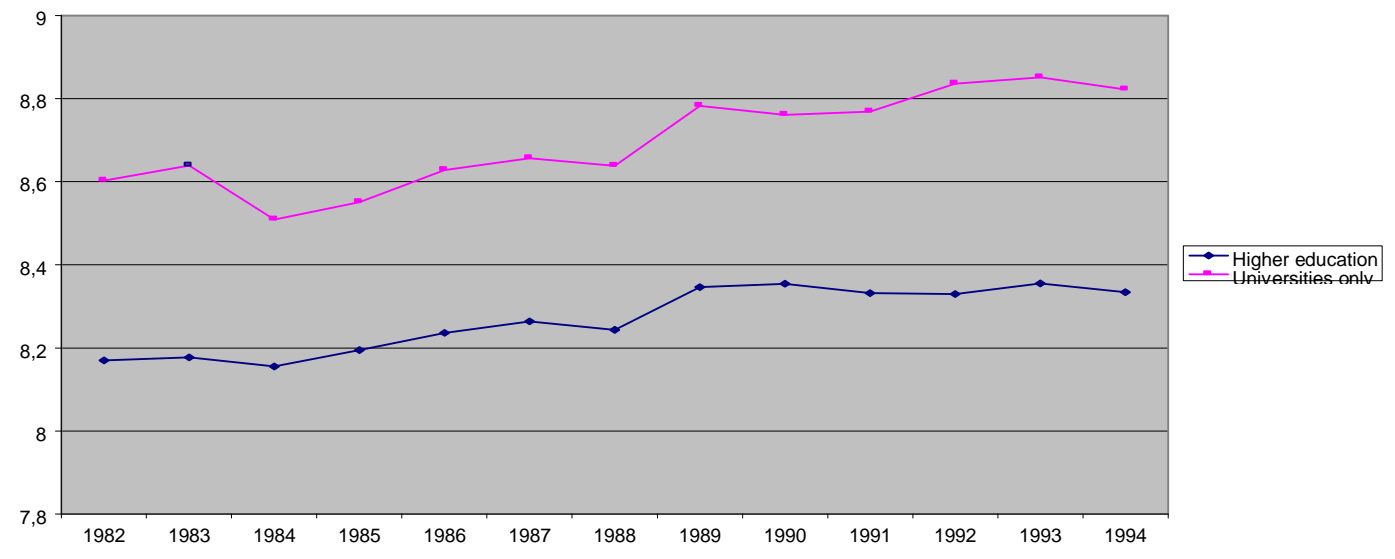

Figure 3: High school GPA of first-year students. 


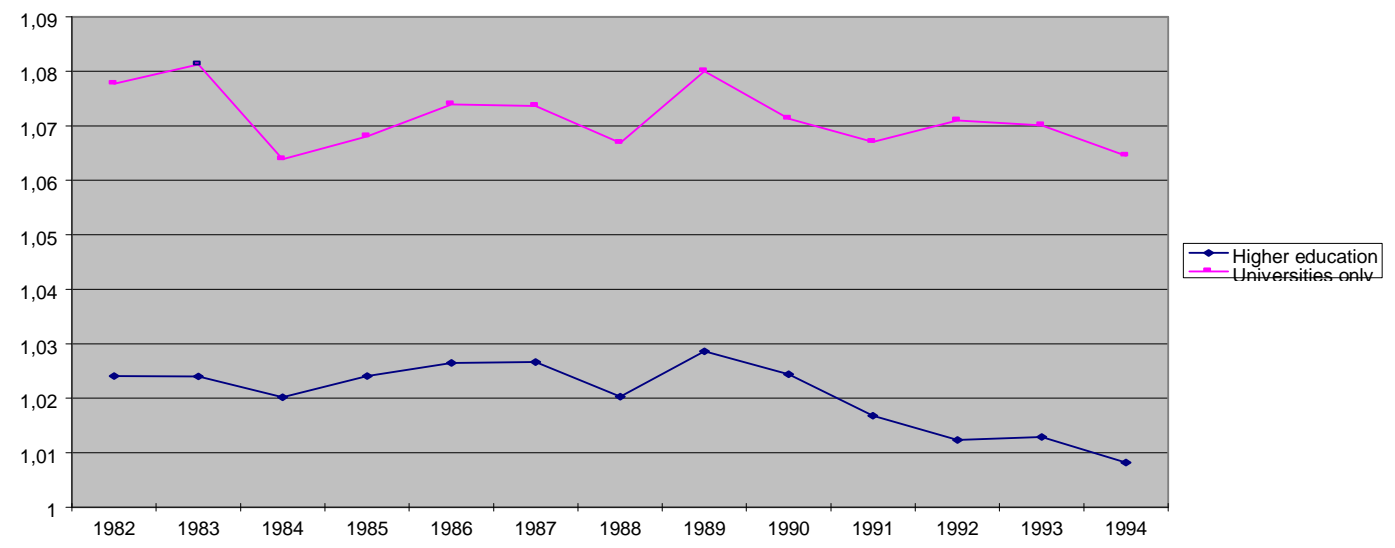

Figure 4: High school GPA of first-year students relative to high school cohort average. 